\title{
IDEOLOGIA EM MARX E EM GRAMSCI
}

\author{
Fabio Frosini *
}

\begin{abstract}
RESUMO
A tese mais difundida sobre a noção gramsciana de ideologia é que ela depende mais de Lênin que de Marx, enquanto é uma concepção neutra e descritiva e não crítica. Neste artigo, demonstra-se que esta tese é falsa. Para chegar a esta conclusão, mostrarei que: A) a noção de ideologia como "falsa consciência" é o resultado de uma simplificação realizada por Engels, e que a noção de ideologia elaborada nos anos 1840 por Marx e Engels é muito mais complexa; B) esta inclui, de fato, a capacidade de substituir de modo imaginário a práxis social real. Enquanto tal, a ideologia implica também que a sua crítica não pode ser um "desvelamento" teórico, mas a construção política, prática de um substituto real deste substituto imaginário; C) a conclusão é que só Gramsci, entre os marxistas, apreendeu a complexidade do conceito de ideologia e o desenvolveu de modo consequente como sinônimo de um processo de constituição de verdade/realidade.
\end{abstract}

Palavras-chave: Karl Marx. Antônio Gramsci. Ideologia e verdade. Hegemonia.

\begin{abstract}
According to the accepted reading, Gramsci's notion of ideology arises more from Lenin than from Marx, since it is neutral and descriptive rather than critical. In this paper, however, we show this argument to be incorrect. To reach to this conclusion we shall argue that: A) the notion of ideology as "false consciousness" results from a simplification made by Engels, whereas the concept of ideology, as it is elaborated by Marx and Engels in the 1840s, is much more multifaceted; B) the concept of
\end{abstract}

\footnotetext{
* Pesquisador em História da Filosofia no Departamento de Ciências do Homem da Universidade de Urbino-Itália. Membro da International Gramsci Society-Italia, membro de Comitê Científico da Fundação Instituto Gramsci-Roma-Itália. E-mail: fabio.frosini@, uniurb.it
} 
ideology includes in fact the ability to substitute the real social praxis with an imaginary one. As such, the notion of ideology implies also that its critique cannot be reduced to a mere theoretical "unveiling", but rather it must consist in the political, practical production of a real substitute for the imaginary one; and C) the conclusion is that only Gramsci, among marxists, grasped the complexity of the notion of ideology and developed it in a consistent manner as a synonym for a process of truth/reality constitution.

Keywords: Karl Marx. Antonio Gramsci. Ideology and truth. Hegemony.

\section{1 "Falsches Bewusstsein""}

O objeto da minha intervenção é uma noção que na história do marxismo é tão difundida quanto obscura: ideologia. Se considerarmos o Marx-Engels Verzeichnis, que em 1989 concluiu a publicação dos Werke, o termo Ideologie é distinto em duas grandes acepções, uma geral e uma particular. Em geral, ideologia equivale a Überbau (superestrutura); em particular, essa, por sua vez, significa "forma da consciência social de caráter idealístico e limitada por uma perspectiva de classe"2.

Mais adiante, voltarei à primeira acepção. No momento, nos deteremos na segunda. Esta, como se mostra evidente, gira em torno do manuscrito que os editores póstumos intitularam, em 1932, Die deutsche

\footnotetext{
1 Falsa consciência.
}

2 MARX, K.; ENGELS, F. Sachregister (Band 1-39). Berlin: Dietz, $2009^{2}$ (1989), p. 310. Para uma apresentação geral do conceito em Marx, ver LUPORINI, C.; PAPI, F. Ideologia. In: PAPI, F. Dizionario Marx Engels. Bologna: Zanichelli, 1983, p. 195-197; REHMANN, J. Theories of ideology. The powers of alienation and subjection. Leiden: Brill, 2013, p. 21-60. Uma rápida reconstrução das diversas acepções de ideologia de Marx a Gramsci em FERGNANI, F. Il concetto di ideologia nel materialismo storico. In: "Rivista di filosofia", LVI, 1965, n. 2, p. 195-212; e ainda In: FERGNANI, F. Marxismo e filosofia contemporânea. Cremona: Gianni Mangiarotti Editore, [s.d., mas em 1964], p. 75-89. Também, para um panorama mais amplo, que compreende o marxismo, mas não se limita a este, ver EAGLETON, T. Ideology: an introduction. London/New York: Verso, 1991; S. ŽIZEK. Mapping ideology. London/New York: Verso, 1994. Sobre Gramsci, ver LIGUORI, G. Ideologia. In: FROSINI, F.; LIGUORI, G. Le parole di Gramsci. Per un lessico dei quaderni del carcere. Roma: Carocci, 2004, p. 131-149; REHMANN, J. 2013, p. 117-146. 
Idelogie ( $A$ ideologia alemã). Mas, muito antes, essa se tornou popular no marxismo da Segunda Internacional por Engels que, em uma carta de 1893 a Franz Mehring, cunhou também para esta uma definição sintética e aparentemente clara, que depois todos adotaram como "oficial": a ideologia é a "consciência falsa" :

a ideologia - escreve Engels - é um processo que o considerado pensador desenvolve conscienciosamente [mit Bewusstsein], mas com uma consciência falsa [falschen Bewusstsein]. As verdadeiras forças motrizes que movem este processo [de pensamento] lhes restam desconhecidas, do contrário não se trataria, exatamente, de um processo ideológico ${ }^{4}$.

A ideologia não se caracteriza pela desonestidade do ideólogo. Engels, aliás, escreve que ele cumpre o próprio trabalho "conscienciosamente". Então, o ideólogo não tem intenção de "enganar": ele, ao contrário, "crê" dizer coisas verdadeiras. O verdadeiro pensador não se opõe ao ideólogo pela sua desonestidade, mas porque é capaz de "preencher" a sua consciência de conteúdos reais, que são as verdadeiras "forças motrizes" do processo mental.

Enfim, a diferença entre consciência "falsa" e consciência "verdadeira" está na capacidade de individuar o modo como os pensamentos nascem. Como Engels escreve com grande clareza em Ludwig Feuerbach, publicado em opúsculo em 1888, tem-se ideologia quando "se tratam os pensamentos como substâncias independentes, que se desenvolvem umas das outras, submetidas somente às próprias leis". Aos ideólogos, acrescenta,

permanece necessariamente ignorado [unbewußt] o fato de que as condições materiais da vida dos homens, e em cujas cabeças se desenvolve este processo de pensamento, determinam em última

3 ENGELS, F. Carta a Franz Mehring, 14 julho 1893. In: MARX, K.; ENGELS, F. Werke, Bd. 39. Berlin: Dietz, 1968, p. 96-100: 97.

4 Ibidem. ("Die Ideologie ist ein Prozess, der zwar mit Bewusstsein vom sogenannten Denker vollzogen wird, aber mit einem falschen Bewusstsein. Die eigentlichen Triebkräfte, die ihn bewegen, bleiben ihm unbekannt, sonst wäre es eben kein ideologischer Prozess"). 
instância este processo [...], porque em caso contrário a inteira ideologia desapareceria. ${ }^{5}$

As formas principais da ideologia são, segundo Engels, o "poder estatal", o "direito público e privado", a "filosofia" e a "religião". Esta última "é a mais distante da vida material e parece ser a mais estranha a ela"

Pelo que foi aqui apresentado, mostra-se claro que para Engels a ideologia é um processo de pensamento caracterizado por uma dupla falta: falta de uma consciência científica correta do próprio processo de formação, e falta de um contato real com a vida material. Somente enquanto "consciência" e "contato real" coincidem, ele pode equiparar sob a categoria de "ideologia" a religião, o direito, a filosofia e o poder estatal. Evidentemente, entre estes fenômenos subsiste um nexo preciso: quanto mais o processo mental se distancia do processo da vida material - isto é, do processo da produção da vida material -, tanto mais este conquista universalidade com prejuízo da verdade. Como consequência, a filosofia é mais "verdadeira" (ou menos "falsa") do que a religião, o direito é mais "verdadeiro" do que a filosofia, e o poder estatal é mais "verdadeiro" do que o direito. Ao contrário, quanto mais um determinado processo mental reflete fielmente e de perto um determinado processo social, tanto menos este é universal e mais é verdadeiro.

Mas, dado que para Engels o materialismo histórico é "científico", deve existir também uma forma de universalidade capaz de se distanciar do dado imediato sem perder "consciência" do processo de produção do pensamento. Dito de outra forma, existe uma forma de saber, o materialismo histórico, que é teórico e, portanto universal, mas não falso, não ideológico, porque é capaz de individuar o nexo real entre o pensamento e a realidade ou, mais precisamente (como Engels se expressa), entre a "consciência" e

5 ENGELS, F. Ludwig Feuerbach und der Ausgang der deutschen klassischen Philosophie. In: MARX, K.; ENGELS, F. Werke. Bd. 21. Berlin: Dietz, 1962, p. 303. ("Ideologie, d.h. Beschäftigung mit Gedanken als mit selbständigen, sich unabhängig entwickelnden, nur ihren eignen Gesetzen unterworfnen Wesenheiten. Daß die materiellen Lebensbedingungen der Menschen, in deren Köpfen dieser Gedankenprozeß vor sich geht, den Verlauf dieses Prozesses schließlich bestimmen, bleibt diesen Menschen notwendig unbewußt, denn sonst wäre es mit der ganzen Ideologie am Ende").

${ }^{6}$ Ibidem, p. 302-303. 
a "vida material". Sobre o modo com que este nexo real pode se instituir corretamente, Engels se deteve muitas vezes no Antidühring, no Ludwig Feuerbach, na Evolução do socialismo da utopia à ciência. Mas é na oração fúnebre para Marx, que Engels deu a síntese mais reveladora do seu modo de entender esta relação. Aqui, após ter afirmado que o amigo falecido era comparável a Darwin, porque "como Darwin descobriu a lei de desenvolvimento da natureza orgânica, assim Marx descobriu a lei do desenvolvimento da história humana"7. Engels assim resume a teoria do materialismo histórico: "o simples dado de fato, até agora sepultado sob um manto de ideologias, que os homens antes de qualquer outra coisa, primeiramente devem comer, beber, morar e se vestir, $e$ depois fazer política, ciência, arte, religião etc."8

A qual "manto de ideologias" se refere Engels em 1883, é difícil dizer. Na realidade, se se assumem os seus vários pronunciamentos nos livros lembrados há pouco, percebe-se que Engels sempre repete a polêmica anti-idealistíca da qual o materialismo histórico nascera em meados dos anos 40, adotando de modo mais ou menos consciente uma abordagem de tipo feuerbachiano. Esta abordagem está muito evidenciada nas linhas ora citadas: o corpo precede o espírito, e o espírito - desenvolvendo-se do corpo - torna-se autônomo e retorna sobre o corpo para assenhoreálo como uma potência estranha. Deste modo Engels explica a gênese da inteira superestrutura: como uma série de "esferas" que se "separam" e se "distanciam" da produção da vida material, isto é, da "vida" concreta, e que se tornando autônomas "parecem" viver de vida própria. As duas esferas - vida material e cultura - são separáveis e completamente autônomas. Engels provavelmente não pensa que exista um momento da vida da humanidade, no qual se produz a vida material em ausência

ENGELS, F. Das Begräbnis von Karl Marx. In: MARX, K.; ENGELS, F. Werke. Bd. 19. Berlin: Dietz, 1962, p. 335-339: 335. ("Wie Darwin das Gesetz der Entwicklung der organischen Natur, so entdeckte Marx das Entwicklungsgesetz der menschlichen Geschichte").

8 Ibidem.. ("[...] die bisher unter ideologischen Überwucherungen verdeckte einfache Tatsache, daß die Menschen vor allen Dingen zuerst essen, trinken, wohnen und sich kleiden müssen, ehe sie Politik, Wissenschaft, Kunst, Religion usw. treiben können”). Grifos meus. 
de "política, ciência, arte, religião etc." . Todavia, afirma claramente que todas estas atividades não são essenciais para organizar a produção da vida material. Como consequência, a compreensão correta do nexo entre vida material e ideologias, isto é, o materialismo histórico, consiste na derivação materialística pelas segundas da primeira e na afirmação da não independência das ideologias. Aqui está a raiz de todo o "reducionismo" que atravessou a história do marxismo com inúmeras variantes, e que contribuiu para envolver as discussões teóricas do marxismo em questões insolúveis, como aquela da "ação recíproca" ou da "retroação" da superestrutura sobre a base material, ou aquela da "determinação em última instância".

\section{A ideologia como "função social"}

Foi dito que, apresentando o conceito de ideologia, Engels sempre pressupõe a polêmica dos anos quarenta contra o idealismo de Hegel e da esquerda hegeliana. O seu papel no estabelecimento do "marxismo" foi tal que, a ideologia sempre foi lida, de fato, sob a luz daquela polêmica, e o marxismo como uma confutação materialística do idealismo. Mas se se toma a já lembrada Ideologia alemã, pode-se constatar como na realidade a polêmica aqui conduzida não seja reduzível aos termos individuados por Engels, e por ele enfim sintetizados em Ludwig Feuerbach na distinção de "pensamento e ser" como a "grande questão fundamental de toda filosofia, em especial modo daquela moderna" 10 . O que na Ideologia alemã define as condições de nascimento da ideologia não é nem uma resposta errada (idealística) à questão da relação entre pensamento e ser, nem a feuerbachiana autonomização do Estado, mas um fato muito específico: a "divisão do trabalho material e mental". Somente a partir deste momento "a divisão do trabalho se torna realmente uma divisão" e a

9 De fato, o seu $A$ origem da família, da propriedade privada e do Estado. Trabalho relacionado com as investigações de L. H. Morgan (Der Ursprung der Familie, des Privateigentums und des Staats. Im Anschluß an Lewis H. Morgans Forschungen), de 1884, demonstra o contrário.

${ }^{10}$ ENGELS, F. Ludwig Feuerbach und der Ausgang der deutschen klassischen Philosophie, Op. Cit., p. 274. ("Die große Grundfrage aller, speziell neueren Philosophie ist die nach dem Verhältnis von Denken und Sein"). 
consciência pode realmente imaginar ser alguma coisa de diferente da consciência da práxis existente, de se representar realmente alguma coisa, sem se representar coisa alguma de real - a partir deste momento a consciência é capaz de se emancipar do mundo e passar à elaboração da 'pura' teoria, teologia, filosofia, moral etc. ${ }^{11}$.

Se a caracterização da série de formações mentais que surgem sobre esse pressuposto coincide com o quanto Engels diz a respeito (estas são formas "ilusórias", vazias de conteúdo real etc.), bem diferentemente vem aqui apresentado ao menos implicitamente o modo de ver "científico". Este modo de ver deve ser desenvolvido a partir do conceito de "divisão do trabalho", e da sua verdadeira origem, que é a divisão entre trabalho manual e trabalho intelectual. Esta dicotomia se acompanha à divisão em classes da sociedade, mas não se identifica com esta: a distinção entre trabalho manual e intelectual não coincide com aquela entre dominados e dominantes, mas está presente de modo diverso em ambos os campos ${ }^{12}$. A ideologia nasce, porque a divisão do trabalho manual e intelectual determina uma ruptura da "consciência" da "práxis existente", mas esta ruptura atinge todos, em medida e modo diferentes. Isto certamente se "condensa" em figuras bem reconhecíveis como primeiramente o sacerdote, em seguida o filósofo, o jurista, o político, o cientista etc. ${ }^{13}$ Mas a dicotomia entre aspectos manuais e intelectuais do trabalho se encontra também nas funções sociais subordinadas.

11 MARX, K.; ENGELS, F. Die deutsche Ideologie. In: MARX, K.; ENGELS, F. Werke. Bd. 3. Berlin: Dietz, 1969, p. 31. ("Die Teilung der Arbeit wird erst wirklich Teilung von dem Augenblicke an, wo eine Teilung der materiellen und geistigen Arbeit eintritt. Von diesem Augenblicke an kann sich das Bewußtsein wirklich einbilden, etwas Andres als das Bewußtsein der bestehenden Praxis zu sein, wirklich etwas vorzustellen, ohne etwas Wirkliches vorzustellen - von diesem Augenblicke an ist das Bewußtsein imstande, sich von der Welt zu emanzipieren und zur Bildung der „reinen“ Theorie, Theologie, Philosophie, Moral etc. überzugehen").

12 Cfr. BALIBAR, E. La philosophie de Marx. Paris: La Découverte, 1993. (Capítulo III).

13 Cfr. MARX, K. L. Feuerbach: "Religiosos, juristas, politicos. Juristas, politicos (pessoas do Estado em geral), moralistas, religiosos". (In: MARX, K.; ENGELS, F. Werke. Bd. 3. Op. Cit., p. 539). ("Religiösen, Juristen, Politiker. Juristen, Politiker (Staatsleute überhaupt), Moralisten, Religiöse $<$ n $>$ "). E cfr. também MARX, K.; ENGELS, F. Die deutsche Ideologie. Op. Cit, p. 31, anotação marginal de Marx: "Primeira forma dos ideólogos, padres" ("Erste Form der Ideologen, Pfaffen"). 
Aqui se entrevê outra acepção de ideologia: que não deve ser entendida somente como falta ou esvaziamento da essência plena do ser humano, mas também como uma precisa função social ${ }^{14}$, que se entrelaçando com a estrutura da subordinação, "dá forma" à sociedade com base na divisão social primária que é a "diferença intelectual"15. O que nasce é uma série de representações gerais - do Estado à divindade - cuja validade e função está exatamente em substituir a perdida "consciência da práxis existente", ao tornar possível uma forma de consciência e de consciência de conjunto, que anule em forma imaginária a dicotomia entre trabalho manual e intelectual. O caráter imaginário desta anulação é a prestação específica da função ideológica.

Portanto, a crítica das ideologias não consiste somente em reconduzir as ideias à produção da vida material, mas também em encontrar uma substituição (real) a esta substituição (imaginária). Mas isso não poderá ser, por sua vez, uma representação teórica, porque é precisamente o caráter só teórico do universal, isto é que determina a sua falsidade. A crítica das ideologias deverá, então, ser um fato prático, político. Já na Ideologia alemã, Marx indica claramente o modo como esta passagem à prática pode ter lugar, sem que isto implique em uma regressão à mera e imediata "consciência da práxis existente". Trata-se sim de pensar a vida material, mas na plenitude das suas relações, não reduzindo a complexidade da sociedade dividida em classes, mas eventualmente, ao contrário, denunciando o indevido empobrecimento, ao qual essa divisão submete a potência global da cooperação social ${ }^{16}$.

Qualquer redução desta tarefa (a produção de uma substituição real da consciência da práxis social) a uma questão pertencente a algum "sujeito" (individual ou coletivo), que deveria introduzir modificações em uma história pensada como "objeto", comportaria um seu fatal

14 Cfr. LUPORINI, C.; PAPI, F. Ideologia. Op. Cit., p. 196: "No materialismo histórico mais maduro [...] as 'formas ideológicas' não mais aparecerão somente como simples 'sublimações', mas como verdadeiras e próprias funções (ainda que nunca denominadas como tais) da vida real dos homens".

15 Esta expressão é introduzida por BALIBAR, E. La philosophie de Marx. Op. Cit., p. 4953, para substituir e precisar a de "divisão do trabalho manual e intelectual".

16 Este aspecto da Ideologia alemã destaca-se oportunamente In: BASSO, L. Socialità e isolamento. La singolarità in Marx. Roma: Carocci, 2008. (Cap. 2). 
empobrecimento. A definição do comunismo como "o movimento real que abole o atual estado de coisas" 17 considera exatamente as dificuldades que traz a crítica prática das ideologias.

Se a palavra "comunismo" tem um sentido, este deve coincidir, portanto, com a mesma história, enquanto essa se assuma na complexidade das relações e das possibilidades que contém. Neste sentido, o comunismo nãoé uma ideologia, porque, como Marx e Engels repetem em vários passos, este não coincide com nenhuma doutrina, não é um pensamento excogitado, não é um princípio a ser realizado ${ }^{18}$. Este é, ao contrário, um conjunto de "fatos", que não são fatos, mas complexos de relações que contêm tanto as causas da subordinação quanto as da sua supressão. É por isso que na Ideologia alemã os conceitos de comunismo e de "pressupostos reais" são definidos de modo bastante similares. Os "pressupostos reais" são aqueles dos quais a análise deve tomar os movimentos se não quer ser ideológica. São "os indivíduos reais, a sua ação e as suas condições materiais de vida, tanto aquelas que estes encontraram já existentes, quanto aquelas produzidas pela própria ação deles"19. Estes "pressupostos" são reais enquanto não são "arbitrários" 20 , ou seja, a sua individuação não depende da escolha subjetiva; ao contrário, a mesma atividade da escolha é possibilitada e ao mesmo tempo condicionada pela sua existência. Condicionada, porque estes "pressupostos" não são neutros: estes correspondem a condições de subordinação e ao exercício de um poder. Tais pressupostos não são nem mesmo "coisas", porque são um entrelaçamento entre três elementos: os indivíduos em condições de vida sempre específicas, as relações que

17 MARX, K. ENGELS, F. Die deutsche Ideologie. Op. cit., p. 35. ("Der Kommunismus ist für uns nicht ein Zustand, der hergestellt werden soll, ein Ideal, wonach die Wirklichkeit sich zu richten haben [wird]. Wir nennen Kommunismus die wirkliche Bewegung, welche den jetzigen Zustand aufhebt").

18 Cfr. ENGELS, F. Die Kommunisten und Karl Heinzen. In: MARX, K.; ENGELS, F. Werke. Bd. 4. Berlin: Dietz, 1959, p. 321-322; e MARX, K.; ENGELS, F. Manifest der kommunistischen Partei. In: MARX, K.; ENGELS, F. Werke. Bd. 4. Belin: Dietz, 1959, p. 474-475, 480-481. E ainda cfr. ENGELS, F. Die Entwicklung des Sozialismus von der Utopie zur Wissenschaft. In: MARX, K.; ENGELS, F. Werke. Bd. 19, Op. Cit., p. 210. ("Diese Mittel sind nicht etwa aus dem Kopfe zu erfinden, sondern vermittelst des Kopfes in den vorliegenden materiellen Tatsachen der Produktion zu entdecken").

19 MARX, K.; ENGELS, F, Die deutsche Ideologie, Op. Cit., p. 20.

20 Ibidem. 
os condicionam e a ação com a qual estes indivíduos modificam estas condições. Dito de outra forma: reconhecer a realidade destes pressupostos implica no reconhecimento da sua historicidade, isto é, do fato que estes "pressupostos" são, por sua vez, expressões de relações de poder, também estas atravessadas, como qualquer outra relação social, pela "diferença intelectual". Mas o reconhecimento da sua historicidade corresponde ao reconhecimento do fato de que no poder está sempre presente também a resistência a este poder, na estrutura está presente a transformação.

\section{Os dois lados da ideologia}

Na segunda metade dos anos 40, Marx e Engels elaboram então um conceito de ideologia muito mais rico do que o modo como eles mesmos o entenderão mais tarde. Entre A ideologia alemã, a Miséria da filosofia e o Manifesto se delineia uma acepção de ideologia como função específica ou potência social, que remete como sua crítica a um movimento teórico e prático ao mesmo tempo, que Marx e Engels chamam neste período "comunismo" como "movimento real" capaz de se identificar com todas as relações e, portanto, de criticar praticamente a subordinação em todos os lugares e em todos os níveis da sociedade ${ }^{21}$. Se a ideologia é entendida nesta acepção, a esta, como substituto imaginário da completude da práxis social, se opõe a realização teórico-prática coletiva daquela mesma práxis, que consiste na restituição daquela práxis (que na história das sociedades divididas em classes se tornou sempre funcional à subordinação) à cooperação social. Isso, porém não quer dizer que a ideologia como substituto imaginário da completude da práxis social seja somente um instrumento de dominação. Ao contrário, a ideologia não poderia ser um substituto imaginário de algo, se não conservasse pelo menos um traço deste objeto ausente, mesmo que seja em forma desfigurada. E por outro lado, que o comunismo não seja uma ideologia no sentido de substituto imaginário da práxis, não quer dizer que seja uma ciência, uma teoria, um conjunto de leis. Ao contrário, enquanto incindivelmente teórico e prático, o comunismo como "movimento real" é ideológico em um significado

\footnotetext{
${ }^{21}$ A esta ideia corresponde a definição do "comunista" como "materialista prático" presente na Ideologia alemã (MARX, K; ENGELS, F. Die deutsche Ideologie, Op. Cit., p. 42: “[...] für den praktischen Materialisten, d.h. Kommunisten [...]").
} 
preciso e limitado, enquanto o comunismo é acompanhado por uma série de representações universalizadas em uma massa politicamente ativa.

Como se vê, existe uma dupla implicação da ideologia com a práxis, e da práxis com a ideologia, que explica porque, se se considera o conceito de ideologia em Marx dos anos 40 em diante, até o Prefácio de para a crítica da economia política (1859), pode-se constatar que tal conceito é atravessado por uma dúplice instância, cada uma das quais prevalece relativamente sobre a outra, a depender da conjuntura concreta, assim, de um lado a ideologia é a esfera imaginária, da qual é necessário prescindir se se entende fazer a história real das sociedades; de outro a ideologia é a dimensão concreta na qual os homens levam adiante e pensam as suas lutas. Não é possível seguir aqui em detalhe estas situações. Basta dizer que a primeira acepção é pressuposta na distinção entre o que os homens dizem de si e o que realmente são, que é cunhada na Ideologia alemã $^{22}$, retorna no Dezoito Brumário de Luis Bonaparte ${ }^{23}$ (1852) e é enfim codificada no Prefácio de para a crítica da economia política ${ }^{24}$ (1859); e a segunda atravessa a Miséria da filosofia, o Manifesto, As lutas de classe na França e se reencontra no mesmo Prefácio de 1859. Neste último texto, as duas componentes da noção de ideologia estão expressas na mesma frase. Discutindo as épocas de revolução, que são determinadas pelo conflito entre forças produtivas sociais e relações de produção, Marx escreve que é necessário distinguir cuidadosamente

a subversão material nas condições da produção econômica, que deve ser constatado fielmente com o método das ciências naturais, e as formas jurídicas, políticas, religiosas, artísticas ou filosóficas, em uma palavra: as formas ideológicas, em cujo terreno os homens se tornam conscientes deste conflito e o resolvem. Assim como não se julga o que um indivíduo é por aquilo que ele parece a si mesmo, tanto menos se pode julgar uma tal época de subversões pela consciência que essa mesma se formou, mas principalmente se deve explicar esta

22 Cfr. Idem, Op. Cit., p. 26.

23 Cfr. MARX, K. Der achtzehnte Brumaire des Louis Bonaparte. In: MARX, K.; ENGELS, F. Werke. Bd. 8. Berlin: Dietz, 1960, p. 139.

24 Cfr. MARX, K. Zur Kritik der politischen Ökonomie, In: MARX, K.; ENGELS, F. Werke. Bd. 13, Berlin: Dietz, 1961, p. 9. 
consciência pelas contradições da vida material, pelo conflito existente entre as forças produtivas sociais e as relações de produção ${ }^{25}$.

Como se pode constatar, de uma parte o plano da representação e o plano da realidade são analiticamente separados, de outra há um reconhecimento não pequeno da função das ideologias, como lugar em que o conflito real se torna "consciente" e permite, deste modo, se mover ativamente neste. Porém, também é claro que, enquanto se permanecer dentro do espaço delimitado pelo materialismo histórico que aqui Marx sintetiza, esta oscilação é destinada a se perpetuar, criando não poucos problemas seja à crítica da ideologia, seja à necessidade de pensar a ação política a partir da dinâmica econômica. Somente se a ideologia é pensada como uma função social específica, e como consequência, a superestrutura não é mais reduzida à aparição derivada e secundária em relação à base material, a política pode ser pensável. Em caso contrário, a política é, em modo contraditório, ou reduzida a "expressão" de tendências presentes na base, e, portanto privada de uma realidade própria, ou separada da base para poder receber esta realidade, e isolada em forma "autônoma".

Mas há mais, porque o mesmo estatuto do marxismo se torna pensável em modo coerente somente se se libera da acepção de ideologia como concatenação de pensamentos desvinculados do contato com a vida real, a favor da ideologia como substituto imaginário da consciência plena e imediata da práxis social. Se, de fato, a alternativa à primeira é um reducionismo economicístico (que pode ser variadamente amenizado, mas permanece sempre tal), a alternativa à segunda acepção é, por sua vez, $a$ questão da unidade de teoria e prática, de trabalho intelectual e trabalho

\footnotetext{
${ }^{25}$ MARX, K.Zur Kritikderpolitischen Ökonomie, Op. Cit., p. 9. ("In der Betrachtung solcher Umwälzungen muß man stets unterscheiden zwischen der materiellen, naturwissenschaftlich treu zu konstatierenden Umwälzung in den ökonomischen Produktionsbedingungen und den juristischen, politischen, religiösen, künstlerischen oder philosophischen, kurz, ideologischen Formen, worin sich die Menschen dieses Konflikts bewußt werden und ihn ausfechten. Sowenig man das, was ein Individuum ist, nach dem beurteilt, was es sich selbst dünkt, ebensowenig kann man eine solche Umwälzungsepoche aus ihrem Bewußtsein beurteilen, sondern muß vielmehr dies Bewußtsein aus den Widersprüchen des materiellen Lebens, aus dem vorhandenen Konflikt zwischen gesellschaftlichen Produktivkräften und Produktionsverhältnissen erklären").
} 
manual. E se no primeiro caso o marxismo tende irresistivelmente a recair em um costumeiro modelo de ciência "teórica" - pelo qual puderam existir uma economia marxista, uma ciência política marxista, uma filosofia marxista, uma estética marxista etc., sem que isto tenha significado minimamente uma crítica real do "cânon" fundamental do "saber" - no segundo caso o marxismo nasce exatamente da crítica à divisão primária entre teoria e prática, da qual a "ciência" pode nascer. Em suma, o marxismo pode realmente ser uma filosofia que entende transformar o mundo, e não somente interpretá-lo, somente se confere à ideologia uma realidade específica, reconhecendo a função que esta desenvolve, não somente de bloco e ilusão, mas também de mobilização e constituição de verdade.

\section{O “valor gnoseológico" da superestrutura}

Este é, exatamente, o caminho que entre os marxistas somente Antonio Gramsci enveredou de modo consequente e coerente. Em seguida ao que foi dito em linhas gerais, não surpreenderá constatar que exatamente porque Gramsci repensa o conceito de ideologia como função da vida real, até incluir nesta tanto o bloco das energias sociais, quanto a sua mobilização, tanto a crítica do erro quanto a constituição de verdade, ele pode pensar o marxismo como teoria realmente revolucionária. Dito de outra forma: a solução do enigma da ideologia se reflete sobre toda a concepção do estatuto do marxismo.

Desta pesquisa poderiam-se indicar, já nos escritos juvenis de Gramsci, numerosos traços, mas aqui me limitarei a lembrar um só passo, que remonta a maio de 1918:

Marx - escreve Gramsci - escarnece das ideologias, mas é ideólogo enquanto homem político atual, enquanto revolucionário. A verdade é que as ideologias são risíveis quando são apenas palavras, quando são voltadas a criar confusões, a iludir e sujeitar-se às energias sociais, potencialmente antagonísticas, a um fim que é alheio a estas energias. [...] Mas como revolucionário, isto é, homem atual de ação, [Marx] 
não pode prescindir das ideologias e dos esquemas práticos, que são entidades históricas potenciais, em formação ${ }^{26}$.

Neste passo se anuncia claramente a dúplice exigência de que se falou há pouco: primeiramente, a figura de Marx deve ser entendida como a de um homem político e, portanto, o marxismo como uma filosofia da revolução (e isto é, da revolução também do modo de fazer filosofia) e, como consequência, a noção de ideologia deve ser entendida como função social e nunca como concatenação de pensamentos privados de conteúdo real. Se entendida assim, será possível distinguir da ideologia formas diversas e também opostas, mas ficando sempre no plano histórico concreto de uma "força" imanente a todas as articulações da sociedade.

Levando às extremas consequências, um tema que tinha sido de Antonio Labriola ${ }^{27}$, Gramsci restitui o marxismo integralmente à história: este também é, escreve nos Cadernos do cárcere, "uma superestrutura"28, e como tal a crítica que o marxismo move às ideologias deve poder ser dirigida também ao próprio marxismo ${ }^{29}$. Naturalmente, isto comporta consequências políticas precisas.

Como filosofia, o materialismo histórico - escreve Gramsci no Caderno 4 - afirma teoricamente que toda "verdade" acreditada eterna e absoluta tem origens práticas e representou ou representa um valor

${ }^{26}$ [GRAMSCI, A.]. Astrattismo e intransigenza. In: Jornal "Il Grido del Popolo", n. 720, 11 maio 1918. Atualmente em GRAMSCI, A. Il nostro Marx. 1918-1919. CAPRIOGLIO, S. (Org.). Torino: Einaudi, 1984, p. 15-19: 17.

27 Cfr. LUPORINI, C. La consapevolezza storica del marxismo (1955). In: Dialettica e materialismo. Roma: Editori Riuniti, 1974, pp. 3-41; FROSINI, F. Gramsci e Labriola: lo statuto della teoria e l'autoriflessività. In: DURANTE, L.; VOZA, P. (Org.). La prosa del comunismo critico. Labriola e Gramsci. Bari: Palomar, 2006, p. 249-274; FROSINI, F. Dialettica e immanenza da Labriola a Gramsci. In: BURGIO, A. (Org.). Dialettica. Tradizioni, problemi, sviluppi. Macerata: Quodlibet, 2007, p. 195-218.

28 A edição utilizada por mim (à qual me remeterei com $Q C$ ) é: GRAMSCI, A. Quaderni del cárcere. Edição crítica do Instituto Gramsci aos cuidados de GERRATANA, V. Torino, 1975. Remeter-me-ei também ao número do caderno e do parágrafo. Neste caso: Caderno 4, § 15: QC, 437.

29 Cfr. GRAMSCI, A. QC, Caderno 4, § 40: p. 465. Cfr. LOSURDO, D. Antonio Gramsci dal liberalismo al "comunismo critico". Roma: Gamberetti, 1997, pp. 215-216. 
provisório. Mas o difícil é fazer compreender 'praticamente' esta interpretação pelo que concerne ao próprio materialismo histórico ${ }^{30}$.

Agir com toda a conviç̧ão necessária, sabendo não somente que esta convicção se apoia sobre premissas transitórias, mas que esta mesma ação contribui, transformando o mundo, a tornar não mais atuais aquelas premissas, é “o máximo 'historicismo', a liberação total de todo 'ideologismo', a real conquista do mundo histórico, isto é, o início de uma nova civilidade original" 31 . O marxismo está à altura desta tarefa quando não somente atinge esta verdade "em teoria", mas a coloca em prática na sua ação política.

Nesta conexão entre teoria do marxismo e política concreta, as ideologias desenvolvem um papel decisivo e é, portanto, sobre a correta compreensão da sua natureza e função, que Gramsci considera necessário ater-se. Retomando o Prefácio de para a crítica da economia política, ele observa no Caderno 4: "Marx afirma explicitamente que os homens tomam consciência das suas tarefas no terreno ideológico, das superestruturas, o que não é afirmação pequena de "realidade"" 32 . E em um texto pouco posterior, no mesmo Caderno, acrescenta a pergunta: "Mas esta consciência é limitada somente ao conflito entre as forças materiais de produção e as relações de produção - como materialmente diz o texto marxista - ou se refere a toda consciência, ou seja, a todo conhecimento?"33. E imediatamente especifica que este "problema [...] pode ser resolvido com todo o conjunto da doutrina filosófica do valor das superestruturas ideológicas"34. E no texto seguinte, acrescenta que "a afirmação de Marx de que os homens tomam consciência dos conflitos econômicos no terreno das ideologias tem um valor gnoseológico e não psicológico e moral "35.

30 GRAMSCI, A., $Q C$, Caderno 4, § 40: $Q C$, p. 465.

31 Cfr. GRAMSCI, A. $Q C$, Caderno 4, § 24: $Q C$, p. 443.

32 Idem, Caderno 4, § 15: QC, p. 437.

33 Idem, Caderno 4, § 37: QC, p. 455.

34 Idem, caderno 4, § 37: $Q C$, p. 455.

35 GRAMSCI, A., Caderno 4, § 38: QC, p. 464-465, grifo meu. 
Então, indo além do literal do texto de Marx, é possível realmente reformar o conceito de ideologia, eliminando a sua acepção somente "privativa" e reconhecendo a sua específica função prático-cognitiva, positiva e construtiva. As ideologias não são apenas um modo para organizar uma massa, tornando-a psicologicamente e moralmente compacta. Este elemento é uma consequência de um fato mais originário, que é a função gnoseológica das ideologias. Gramsci diz, em suma, que combatendo as suas lutas, os homens conhecem e que, aliás, se conhece somente nesta forma, "imersa" na concretude da vida prática.

Esta precisão nos ajuda a reconhecer um fato não imediatamente visível: que se Gramsci pode "forçar" o texto de Marx, isto é possibilitado pelo fato de que o conceito de ideologia como forma de consciência é implicitamente ladeado por ele àquele de "pensamento" como "práxis" das Teses sobre Feuerbach:

a questão de saber se ao pensamento humano pertence a verdade objetiva - escreve Marx na segunda tese - não é uma questão da teoria, mas uma questão prática. É na práxis que o ser humano tem de comprovar a verdade, isto é, a realidade e o poder, o caráter terreno do seu pensamento. A disputa sobre a realidade ou não realidade de um pensamento que se isola da práxis é uma questão puramente escolástica ${ }^{36}$.

O conhecimento ou a falta de conhecimento da realidade no terreno das ideologias faz parte de uma dinâmica social, na qual está sempre em jogo o exercício de um domínio de classe, ou a luta para se subtrair a este domínio, ou para eliminá-lo totalmente. O conhecimento está sempre imerso na luta, mesmo quando pretende se livrar desta.

36 MARX, K. [Thesen über Feuerbach]. In: MARX, K.; ENGELS, F. Werke. Bd. 3. Op. Cit., p. 5. ("Die Frage, ob dem menschlichen Denken gegenständliche Wahrheit zukomme - ist keine Frage der Theorie, sondern eine praktische Frage. In der Praxis muß der Mensch die Wahrheit, i.e. die Wirklichkeit und Macht, Diesseitigkeit seines Denkens beweisen. Der Streit über die Wirklichkeit oder Nichtwirklichkeit des Denkens - das von der Praxis isoliert ist - ist eine rein scholastische Frage"). Cfr. THOMAS, P. D. The gramscian moment. Philosophy, hegemony, and marxism. Leiden: Brill, 2009, p. 308, 448.; FROSINI, F. La religione dell'uomo moderno. Politica e verità nei "Quaderni del carcere" di Antonio Gramsci. Roma: Carocci, 2010, p. 76-80. 
Esta identificação de verdade, realidade, poder do pensamento e seu "caráter terreno" (Marx escreve Diesseitigkeit, ou seja, mundanidade, terrestridade) $)^{37}$, é o que Gramsci chama de o "máximo 'historicismo', a liberação total de todo 'ideologismo', a real conquista do mundo histórico". O historicismo gramsciano parte, então, da imanência recíproca de conhecer e ser: a verdade não é um dado a ser descoberto teoricamente, mas um mundo a ser construído na realidade. A restituição do marxismo à história não significa, portanto, uma ideia genérica de comparação das "ideias" aos "tempos" (no sentido de veritas filia temporis). Ao contrário, esta pressupõe uma revolução filosófica, que consiste na correta compreensão da unidade de teoria e prática como essencial para definir o próprio marxismo. Unindo o Prefácio de 1859 às Teses sobre Feuerbach, Gramsci se capacita a pensar rigorosamente esta revolução filosófica, indo além da consciência do próprio Marx.

\section{Ideologia e universalidade}

A partir desta passagem é possível articular o conceito de ideologia nas suas acepções diversas e também opostas. Gramsci introduz uma dúplice distinção entre ideologia como conjunto de "elucubrações arbitrárias de determinados indivíduos" (utopia ${ }^{38}$ ) e ideologia como "superestrutura necessária de uma determinada estrutura", com a especificação de que somente a segunda acepção delimita o terreno em que se formam as vontades coletivas e, portanto acontece a constituição prática da verdade ${ }^{39}$; e, entre a ideologia como "toda particular concepção dos grupos internos da classe que se propõem ajudar a resolução de problemas imediatos e circunscritos", e a filosofia como "a concepção do mundo que representa a vida intelectual e moral (catarse de uma determinada vida prática) de um inteiro grupo social concebido em movimento e visto, portanto, não apenas

37 Sobre este termo em Marx e Feuerbach cfr. FROSINI, F. Da Gramsci a Marx. Ideologia, verità e politica. Roma: DeriveApprodi, 2009, p. 47-53.

38 Sobre esta acepção do termo cf. FROSINI, F. Filosofia e utopia nos Cadernos do Cárcere: Hegel-Marx-Croce. In: Revista "Educação em foco", V, 2000/2001, n. 2, p. 95-114.

39 GRAMSCI, A. Op. Cit., Caderno 7, § 19: QC, p. 868-869. 
nos seus interesses atuais e imediatos, mas também naqueles futuros e mediados" 40 .

Disto, resulta uma gradação que vai da elucubração arbitrária individual, à elaboração política dos problemas de grupos sociais em relação a questões determinadas, a esta mesma elaboração em um plano de universalidade e de cultura ("catarse"), correspondente à comparação dinâmica deste grupo com todos os outros em uma perspectiva nacional e internacional. Sobre todos estes planos, a "cultura" em todas as suas formas (do senso comum à filosofia), e a ideologia que é a sua elaboração, permanecem sempre "afetadas" pela contradição real, pelo conflito social de que Marx fala no Prefácio de 1859. O movimento de "universalização" do plano da elucubração individual àquele da filosofia não é um distanciamento da realidade do conflito, mas a passagem de um estado em que este é simplesmente sofrido, a um em que é sempre melhor compreendido e dominado. A ideologia é sempre afetada pela luta; muda porém o seu grau de potência prática, porque muda o modo com que o caráter conflitual da realidade é interpretado: se passa de uma perspectiva parcial, incapaz de colher o nexo mediante o qual o conflito liga contraditoriamente a inteira sociedade, a uma progressiva totalização, capaz de traduzir uma na outra as perspectivas parciais e, portanto, de ter sobre essas um poder de endereço, porque as compreende na sua respectiva verdade-eficácia.

Ora, se se reflete bem, esta definição de ideologia é modelada sobre aquela que Marx implicitamente adota na Miséria da filosofia. Deste livro, eu já disse que, neste, se define a acepção de ideologia como função específica ou potência social. Gramsci reconhece este ponto, quando escreve que a Miséria da filosofia "é um momento essencial na formação da filosofia da práxis; esta pode ser considerada como o desenvolvimento das Teses sobre Feuerbach"41. Na Miséria da filosofia, Marx contrapõe às excogitações meticulosas e arbitrárias de um Proudhon, a ideologia potente, porque é capaz de representar a função progressiva da burguesia

\footnotetext{
40 Idem, Caderno 10 I, $\S 10: Q C$, p. 1231.

${ }^{41}$ GRAMSCI, A. . Cit., Caderno 13, § 18: QC, 1592. Na primeira redação Gramsci tinha sido muito mais prudente: "a Miséria da Filosofia pode ser considerada em parte como a aplicação e o desenvolvimento das Teses sobre Feuerbach” (Idem, Caderno 4, § 38: QC, 462).
} 
na complexidade dos seus movimentos, de Ricardo, e, a ambas, a "teoria" comunista, consistente na elaboração e tradução recíproca de todas as lutas, sem nenhum limite não só corporativo, mas de classe tout court ${ }^{42}$.

Passa-se de uma ideologia que padece o conflito, e por isso o rejeita (o "lado bom" e o "lado mau" de Proudhon); a uma ideologia (a economia política) que se fortalece pelo conflito, enquanto este ajuda a saturar a sociedade mediante a universalização de um ponto de vista particular, que, porém permanece tal, simplesmente "colocando-se em lugar" do universal; a uma, enfim, que se coloca como a própria teoria do conflito. Somente esta terceira posição - a teoria comunista - eleva o caráter sempre "afetado" pela ideologia a princípio de conhecimento, enquanto não limita arbitrariamente a função das lutas para o conseguimento da hegemonia de uma classe sobre as outras, mas coloca o caráter permanente das lutas na base da própria teoria, fazendo assim do conflito nem um elemento de distúrbio, nem um veículo temporário de constituição hegemônica ${ }^{43}$, mas o terreno permanente do conhecimento. É a mesma progressão entre ideologia arbitrária, ideologia necessária e ideologia-filosofia elaborada por Gramsci. Apoiando-se na Miséria da filosofia, Gramsci pode, assim, subtrair o conceito de ideologia da acepção negativa e privativa de "falsa consciência", e reconectá-lo à verdade, identificando-o com toda modalidade cognitiva, enquanto toda consciência é sempre interna a determinadas relações sociais e condicionada por estas.

\section{Ideologia e hegemonia}

Ao distinguir as três acepções de ideologia em Gramsci, usei o termo "hegemonia" para designar o modo com que a luta ideológica se consolida em estruturas permanentes. Pode-se dizer que a hegemonia "realizada" é

42 Cfr. MARX, K. Misère de la philosophie. Paris: Payot \& Rivages, 2002, p. 177-180; (Cfr. MARX. K. Das Elend der Philosophie. In: MARX, K. ENGELS, F. Werke, Bd. 4. Op. Cit., p. 141-144).

43 Por isso, como escreve Marx, "Les économistes ont une singulière manière de procéder. Il n'y a pour eux que deux sortes d'institutions, celles de l'art et celles de la nature. Les institutions de la féodalité sont des institutions artificielles, celles de la bourgeoisie sont des institutions naturelles. [...] Ainsi il y a eu de l'histoire, mais il n'y en a plus" (MARX, K. Misère de la philosophie. Op. Cit., p. 174-175). 
uma determinada estrutura da verdade, uma estrutura organizacional em um preciso "aparato hegemônico", como êxito de uma série de lutas ideológicas. Se ora examinarmos rapidamente, em conclusão, o conceito de hegemonia, podemos ver como Gramsci recupera aqui o significado da filosofia tradicional, isto é, da ideologia que Engels define como "falsa consciência".

A hegemonia é, de fato, a organização de uma ideologia não somente em uma expressão filosófica individual, mas - graças a uma série de progressões que da filosofia conduzem até o senso comum - em toda a sociedade. Nos Cadernos, Gramsci coloca este conceito no centro do marxismo, porque neste se conectam os dois aspectos da ideologia: o de consciência e o de transformação da realidade. Lutar para conquistar a hegemonia significa transformar o modo de pensar e, portanto de agir e de pensar, de uma inteira massa humana. Portanto, na hegemonia a "livre concatenação de pensamentos" - a que se reduz a ideologia da maneira como é definida por Engels - adquire um valor real, se torna realidade eficaz. Esta unificação de teoria e prática, que a filosofia tradicional havia expressado de modo imaginário no conceito de "espírito", a política hegemônica a coloca em termos realísticos, concretos, historicistas. Aqui está, para Gramsci, a importância de Lênin: no fato de que ele "construiu a doutrina da hegemonia"44 e por este trâmite "pode-se afirmar que a teorização e a realização da hegemonia feita por Ilitch foi também um grande acontecimento "metafísico", 45 .

A realidade do conceito ideológico de "espírito" se define somente através da unificação contraditória, política e cultural, do gênero humano. Se metafísica é toda afirmação de unidade feita prescindindo desta passagem, a elaboração teórica e prática (em um lugar determinado) do método da hegemonia assinala uma ruptura na história da metafísica, ou melhor, na história metafísica da filosofia e da cultura em geral (dado que metafísica é uma atitude, não uma doutrina particular). De fato, a hegemonia pressupõe "que uma massa de homens seja conduzida a pensar coerentemente e

\footnotetext{
44 GRAMSCI, A. Op. Cit., Caderno 10, I, § 12: QC, p. 1235.

45 Idem, Caderno 7, § 35: QC, p. 886.
} 
em modo unitário o real presente" 46 , porque "a realização de um aparato hegemônico [...] cria um novo terreno ideológico, determina uma reforma das consciências e dos métodos de conhecimento" 47 .

A realização de um aparato hegemônico se coloca no mesmo terreno da "metafísica", porque reflete sobre as condições da unidade do gênero humano. Mas o faz em uma maneira completamente nova, identificando a atividade filosófica e ideológica com a produção política concreta daquela unidade:

O caráter da filosofia da práxis é especialmente aquele de ser uma concepção de massa, uma cultura de massa e de massa que opera unitariamente, ou seja, que tem normas de conduta não só universais em ideia, mas "generalizadas" na realidade social. E, portanto, a atividade do filósofo "individual" só pode ser concebida em função de tal unidade social, isto é, também como política, como função de direção política ${ }^{48}$.

Mas esta novidade radical do marxismo não impede de reconhecer também as linhas de continuidade. $\mathrm{O}$ comunismo rompe com a ideia da história como história do domínio de classes, mas ao mesmo tempo é uma necessidade antiquíssima, que acompanha toda esta história. Falando de "metafísica", Gramsci alude exatamente à ambivalência constitutiva da ideologia, que substitui somente em modo imaginário a perdida "consciência da práxis existente". Na ideologia - e sob este conceito Gramsci inclui sejam as filosofias, sejam as religiões - há, portanto, sempre um dúplice estímulo: o do domínio que reafirma a diferença intelectual e o utópico que recolhe as aspirações dos subalternos a uma crítica prática daquela diferença. A filosofia da práxis deve saber levar a sério ambos os aspectos da ideologia.

\footnotetext{
46 Idem, Caderno 11, § 12: QC, p. 1378.

47 GRAMSCI, A. Op. Cit., Caderno 10 II, § 12: $Q C$, p. 1250.

48 Idem, Caderno 10 II, § 31: QC, p. 1271.
} 


\section{Referências}

BALIBAR, E. La philosophie de Marx. Paris: La Découverte, 1993.

BASSO, L. Socialità e isolamento. La singolarità in Marx. Roma: Carocci, 2008.

EAGLETON, T. Ideology: an introduction. London/New York: Verso, 1991.

ENGELS, F. Carta a Franz Mehring, 14 julho 1893. In: MARX, K.; ENGELS, F. Werke, Bd. 39. Berlin: Dietz, 1968.

. Das Begräbnis von Karl Marx. In: MARX, K.; ENGELS, F. Werke. Bd. 19. Berlin: Dietz, 1962.

. Die Entwicklung des Sozialismus von der Utopie zur Wissenschaft.

Werke. Bd. 19, Berlin: Dietz, 1962.

. Die Kommunisten und Karl Heinzen. In: MARX, K.; ENGELS, F.

Werke. Bd. 4. Berlin: Dietz, 1959.

. Ludwig Feuerbach und der Ausgang der deutschen klassischen

Philosophie. In: MARX, K.; ENGELS, F. Werke. Bd. 21. Berlin: Dietz, 1962.

FERGNANI, F. Il concetto di ideologia nel materialismo storico. Rivista di Filosofia, Roma, v. LVI, n. 2, p. 195-212, Julho. 1965, .

. Marxismo e filosofia contemporânea. Cremona: Gianni Mangiarotti Editore, [1964].

FROSINI, F. Da Gramsci a Marx. Ideologia, verità e politica. Roma: DeriveApprodi, 2009.

. Dialettica e immanenza da Labriola a Gramsci. In: BURGIO, A. (Org.). Dialettica. Tradizioni, problemi, sviluppi. Macerata: Quodlibet, 2007, p. 195-218.

. Filosofia e utopia nos cadernos do cárcere: Hegel-Marx-Croce. Revista Educação em Foco, São Paulo, v. 5, n. 2, Set. 2000/2001. p. 95-114 . Gramsci e Labriola: lo statuto della teoria e l'autoriflessività. In: DURANTE, L.; VOZA, P. (Org.). La prosa del comunismo critico. Labriola e Gramsci. Bari: Palomar, 2006. p. 249-274. 
. La religione dell'uomo moderno. Politica e verità nei "Quaderni del carcere" di Antonio Gramsci. Roma: Carocci, 2010.

GRAMSCI, A. Astrattismo e intransigenza, In: Jornal Il Grido del Popolo, n. 720, 11 maio 1918.

GRAMSCI, A. Il nostro Marx. 1918-1919. In: CAPRIOGLIO, S. (Org.). Torino: Einaudi, 1984.

- Quaderni del carcere. Edição crítica do Istituto Gramsci a cura di Valentino Guerratana. Torino: Einaudi, 1975.

LIGUORI, G. Ideologia. In: FROSINI, F.; LIGUORI, G. Le parole di Gramsci. Per un lessico dei Quaderni del carcere. Roma: Carocci, 2004.

LOSURDO, D. Antonio Gramsci dal liberalismo al "comunismo critico". Roma: Gamberetti, 1997.

LUPORINI, C.; PAPI, F. Ideologia. In: PAPI, F. Dizionario Marx Engels. Bologna: Zanichelli, 1983.

LUPORINI, C. La consapevolezza storica del marxismo (1955). In: . Dialettica e materialismo. Roma: Editori Riuniti, 1974.

MARX. K. Das Elend der Philosophie. In: ; ENGELS, F. Werke, Bd. 4. Berlin: Dietz, 1959.

- Der achtzehnte Brumaire des Louis Bonaparte. In:

ENGELS, F. Werke. Bd. 8. Berlin: Dietz, 1960.

. Misère de la philosophie. Paris: Payot \& Rivages, 2002.

. Thesen über Feuerbach. In: ; ENGELS, F. Werke. Bd. 3. Berlin: Dietz, 1969.

. Zur Kritik der politischen Ökonomie. In: ; ENGELS, F. Werke. Bd. 13, Berlin: Dietz, 1961. . L. Feuerbach. In: ; ENGELS, F. Werke. Bd. 3. Berlin: Dietz, 1969.

; ENGELS, F. Die deutsche Ideologie. In: ; ENGELS, F. Werke. Bd. 3. Berlin: Dietz, 1969. 1959. . Manifest der kommunistischen Partei. Werke. Bd. 4. Berlin: Dietz, 
. Sachregister (Band 1-39). 2 ed. Berlin: Dietz, 2009.

REHMANN, J. Theories of ideology. The powers of alienation and subjection. Leiden: Brill, 2013.

S. ŽIZEK. Mapping ideology. London/ New York: Verso, 1994.

THOMAS, P. D. The gramscian moment. Philosophy, hegemony, and marxism. Leiden: Brill, 2009.

Data de registro: $10 / 03 / 2014$

Data de aceite: 23/04/2014 